\title{
Ochratoxin A contamination of the casing and the edible portion of artisan salamis produced in two Italian regions
}

\author{
P. Roncada ${ }^{*}$, A. Altafini ${ }^{1}$, G. Fedrizzi ${ }^{2}$, A. Guerrini ${ }^{1}$, G.L. Polonini ${ }^{2}$ and E. Caprai $^{2}$ \\ ${ }^{1}$ Department of Veterinary Medical Sciences, University of Bologna, via Tolara di Sopra 50, 40064 Ozzano Emilia (BO), \\ Italy; ${ }^{2}$ Chemical Food Department, Istituto Zooprofilattico Sperimentale della Lombardia e dell'Emilia Romagna 'Bruno \\ Ubertini, via P. Fiorini 5, 40127 Bologna, Italy; paola.roncada@unibo.it
}

Received: 20 February 2020 / Accepted: 27 May 2020

(c) 2020 Wageningen Academic Publishers

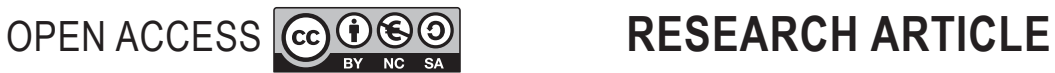

\begin{abstract}
The purpose of this study was to provide data on the presence of ochratoxin A (OTA) in artisan salamis produced in the Campania and Marche regions (Italy). For this aim, 96 different salamis were purchased from farms and small salami factories. Analysis were carried out firstly on the casings of all samples, and in a second step, in the outer and inner edible parts of those samples whose casings were found positive for OTA at concentration levels above the Italian guideline value established for OTA in pork meat $(1 \mu \mathrm{g} / \mathrm{kg})$. The analytical method, based on a sample preparation procedure with immunoaffinity columns, together with analysis by LC-MS/MS, has guaranteed average recoveries between 79.4 and $89.0 \%$, limits of detection (LOD) and quantification (LOQ) of 0.10 and $0.25 \mu \mathrm{g} / \mathrm{kg}$, respectively. OTA was detected in $25.0 \%$ of the analysed casings ( 24 samples) at concentration ranging from 0.25 to $98.52 \mu \mathrm{g} / \mathrm{kg}$. Ten of these samples were from the same production plant in which an additional sampling was carried out, and where a problem of environmental contamination by ochratoxigenic moulds probably exists. The edible parts were mostly uncontaminated, except in 3 samples, 2 of which showed OTA contamination levels above $1 \mu \mathrm{g} /$ $\mathrm{kg}$. The presence of OTA on the casing does not seem to be cause for alarm about the safety of this type of product but it should in any case be monitored. Before slicing the meat for consumption, it is always good practice to peel the casing even if reported as edible on salami label.
\end{abstract}

Keywords: mycotoxins, sausages, food safety, LC-MS/MS

\section{Introduction}

Ochratoxin A (OTA) is a mycotoxin produced by several species of the genera Aspergillus and Penicillium, mainly Aspergillus ochraceus, Penicillium verrucosum, and Penicillium nordicum (Dall'Asta et al., 2010). It has been shown to be nephrotoxic, hepatotoxic, teratogenic and immunotoxic to several species of animals, and to cause kidney and liver tumours in mice and rats (JECFA, 1996). In addition, it is a significant causal determinant of porcine nephropathy (Hald, 1991). OTA has been classified as a possible human carcinogen (Group 2B) by the International Agency for Research on Cancer (IARC, 1993). Literature also reports its possible implication in Balkan Endemic Nephropathy (BEN) (Castegnaro et al., 2006; Pfohl-Leszkowicz et al., 2007), and in Chronic
Interstitial Nephropathy (CIN), a highly similar disease found in North Africa (Hassen et al., 2004), although the most recent studies have shown that OTA plays a minor role in the aetiology of these diseases (Pavlović, 2013; Stiborová et al., 2016).

The products that are most frequently contaminated are: barley, sorghum, corn, wheat and other cereals, legumes, raw coffee beans and various baked products, spices, peanuts, fresh fruit (especially grapes) and dried fruit, raisins, cocoa, beer and wine (EC, 2002; EFSA, 2006; Jørgensen, 2005). OTA has also been found in edible pork by-products, due to the carry-over from naturally contaminated feed and its accumulation in different tissues and organs (blood, kidneys, lungs, heart, liver, spleen, fat and muscle) (Altafini et al., 2017; Persi et al., 2014; Pleadin et al., 2016). However, 
in most cases the presence of OTA in cured meat products could be due to direct contamination with moulds (Battilani et al., 2007; Bertuzzi et al., 2013). It is important to report that in products of animal origin, mycotoxins could also come from other ingredients added during preparation, especially spices (Altafini et al., 2019; Armorini et al., 2016; EFSA, 2006). A study has also shown that the sea salt used for salting meat in the early stages of dry-cured meat processing can be a source of $P$. nordicum, a toxigenic mould which can then proliferate on dried meats and cause OTA contamination (Sonjak et al., 2011). Processed meat products, such as dry-cured ham, fermented sausage and others, are foods of major importance in several European countries, both nutritionally and economically (Meftah et al., 2018). In particular, salami is a typical product of the Italian tradition. In 2016 Italy became the world leader in export of prepared or preserved meat of swine, and salamis represent $17 \%$ of these products (ASSICA, 2018).

Salami is an encased sausage containing even grains of product predominantly obtained from a mixture of minced pork meat and fat in natural or artificial casings. The name derives from the salting operation, necessary to ensure conservation. Besides sea salt, nitrate and/or nitrite and spices, often including sugar, starter cultures and other additives may be added. After being packed into casings, salami is subjected to a fermentation and drying/ripening stage (Fongaro et al., 2015).

At European level, a guidance value for OTA equal to $0.05 \mathrm{mg} / \mathrm{kg}$ was established in complementary and complete feedingstuffs for pigs (EC, 2006a), but not in meat and meat-based products. In Italy, the Ministry of Health has set a guideline value of $1 \mu \mathrm{g} / \mathrm{kg}$ in pork meat and derived products (Ministero della Sanità, 1999). According to a survey carried out in the European Union, meat contribute $1 \%$ to the mean human dietary intake of OTA (EC, 2002), while in a more recent research conducted in the United States it is reported that, among the adult population, pork consumption supposes $15.82 \%$ of the total OTA intake (Mitchell et al., 2017).

The accumulation of OTA by Aspergillus and Penicillium is affected by the amount of inoculum, substrate, water activity, moisture content, temperature, incubation time and by the species of the fungus itself (Rizzo et al., 2002). All these factors interact together, and also fungal growth depend on a combination of these parameters. In addition, optimum conditions for fungal growth are usually different from those for mycotoxin production (Gil-Serna et al., 2015). The published studies indicate that OTA is stable and processing procedures, such as ripening, drying, and storage, have been proved to be ineffective for its reduction in meat products (Monaci et al., 2005; Schiavone et al., 2008). If OTA is produced by moulds growing on the surface of the casing throughout the ripening process, it becomes interesting to evaluate if the accumulation of this mycotoxin is limited to the casing or may penetrate to the inner edible part. This information could be used to implement actions to avoid production of salamis contaminated with OTA.

The aim of this work was to monitor the degree of OTA contamination of the casing and the edible part of artisan salamis produced in the Campania and Marche regions (Italy). The present survey is part of a larger research project monitoring the occurrence of OTA in salamis from several Italian regions. Compared to our previous studies, this research has focused on the presence of the mycotoxin on the casing. A liquid chromatography-mass spectrometry (LC-MS/MS) method was used for analyses of samples.

\section{Materials and methods}

\section{Samples}

In this study, from May to July 2018, a total of 96 salamis produced by traditional artisan techniques were purchased mainly from small family farms located in the provinces of the Italian regions of Campania and Marche. Firstly, 83 salamis of various type (51 from Campania and 32 from Marche) were sampled. From each salami, the casing was removed, and an aliquot was then taken both from the outer portion and from the core. The casing, the inner and outer portion were collected and analysed separately. Precautions were taken to avoid cross-contamination between the different parts. All the samples were stored at $-18{ }^{\circ} \mathrm{C}$. Analysis were performed firstly on the casings of all samples, and in a second step, in the outer and inner edible parts of those samples whose casings were found positive for OTA at concentration levels above the Italian guideline value established for OTA in pork meat $(1 \mu \mathrm{g} / \mathrm{kg})$. After analysis of these 83 samples, further investigations were carried out on the same farm from which the two most contaminate products came by collecting and analysing 13 additional samples of salamis.

\section{Chemicals and reagents}

All solvents and reagents were analytical grade or HPLC grade. The OTA standard and the $\mathrm{U}-\left[{ }^{13} \mathrm{C}_{20}\right]$-OTA standard (internal standard, IS) used to prepare standard solutions for the validation of the applied methodology were purchased from Biopure (Tulln, Austria). Ochraprep ${ }^{\oplus}$ immunoaffinity columns from R-Biopharm AG (Darmstadt, Germany) were used for samples purification. Acetonitrile, acetic acid, sodium phosphate dibasic dihydrate, potassium dihydrogen phosphate anhydrous, potassium chloride and sodium carbonate were purchased from Sigma-Aldrich Co. (St Louis, MO, USA); sodium chloride and sodium sulphate anhydrous were obtained from Panreac (Barcelona, Spain); sodium hydroxide, methanol, and formic acid were purchased from Merck KGaA (Darmstadt, Germany), 
WWR Chemicals (Milano, Italy), and Carlo Erba Reagents (Cornaredo, MI, Italy), respectively. Ultrapure water used throughout the experiments was produced by a Millipore Milli-Q system (Millipore, Bedford, MA, USA).

\section{Chromatographic apparatus}

OTA analysis were performed by LC-MS/MS on an Alliance HT 2695 (Waters, Milford, MA, USA) coupled to a Quattro Ultima Platinum triple-quadrupole mass spectrometer with electrospray ionization source (Micromass, Manchester, UK). Chromatographic separation was achieved in gradient elution mode and at room temperature using an analytical column Luna C18 (2) $100 \AA 100 \times 2.0 \mathrm{~mm} 3 \mu \mathrm{m}$ (Phenomenex, Torrance, CA, USA). The mobile phase consisted of deionized water (solvent A), and acetonitrile (solvent B), both containing $0.2 \%$ formic acid. The gradient program started with $85 \% \mathrm{~A}$ and $15 \% \mathrm{~B}$, reaching $0 \% \mathrm{~A}$ in 5.5 min with linear increase; then return to $85 \% \mathrm{~A}$ in $3 \mathrm{~min}$ and re-equilibration time of $2.5 \mathrm{~min}$, giving a total run time of $11 \mathrm{~min}$. The flow rate of the mobile phase was $0.25 \mathrm{ml} / \mathrm{min}$, and the injection volume was $10 \mu \mathrm{l}$. Based on the structural properties of the analytes, the positive ionization modes $(\mathrm{ESI}+)$ was applied. The parameters were as follows: cone voltage, $45 \mathrm{~V}$; capillary voltage, $4.5 \mathrm{kV}$; source temperature, $120^{\circ} \mathrm{C}$; and desolvation temperature, $350^{\circ} \mathrm{C}$. Mass Lynx TM 4.0 SP4 software (Micromass, Manchester, UK) was used to control the instruments and process the data. The data acquisition was in multiple reactions monitoring (MRM) mode. The ion transitions and mass parameters monitored for OTA and U-[13C20]-OTA are reported in Table 1.

\section{Sample extract preparation}

For the analysis of the casing, $1 \mathrm{~g}$ of minced sample was added with $20 \mathrm{ml}$ of acetonitrile-water solution (80:20) in a centrifuge tube. The mixture was then mixed for 30 min on an horizontal shaker and centrifuged at $48,384 \times g$ for $10 \mathrm{~min}$ at ambient temperature. A $10 \mathrm{ml}$ aliquot of the upper phase was transferred into a clean centrifuge tube, diluted with $10 \mathrm{ml}$ of phosphate buffered saline (PBS) buffer $\mathrm{pH}$ 7.4, and centrifuged as described before. $10 \mathrm{ml}$ of the resulting solution (equivalent to $0.25 \mathrm{~g}$ sample) were then loaded onto an Ochraprep ${ }^{\circledR}$ IAC. Before the immunoaffinity cleanup, $50 \mu \mathrm{l}$ of the $\mathrm{U}-\left[{ }^{13} \mathrm{C}_{20}\right]$-OTA standard solution 10 $\mathrm{ng} / \mathrm{ml}$ was added to each sample as an internal standard (IS) (resulting in a final concentration in the sample of $2 \mathrm{ng} / \mathrm{g}$ ). For the analysis of the edible part of salami, $25 \mathrm{~g}$ of minced sample were weighed in a suitable centrifuge tube, and $10 \mathrm{~g}$ of sodium sulphate anhydrous were added and thoroughly mixed in order to remove any water. After addition of $100 \mathrm{ml}$ of acetonitrile-water solution (80:20), the mixture was mixed for $30 \mathrm{~min}$ on an horizontal shaker and centrifuged at $48,384 \times g$ for $10 \mathrm{~min}$ at ambient temperature. A $4 \mathrm{ml}$ aliquot of the upper phase (equivalent to $1 \mathrm{~g}$ sample) was then transferred into a clean centrifuge tube and diluted with $44 \mathrm{ml}$ of PBS buffer $\mathrm{pH}$ 7.4. Before cleanup, $10 \mu \mathrm{l}$ of the $\mathrm{U}-\left[{ }^{13} \mathrm{C}_{20}\right]$-OTA standard solution at a concentration of $100 \mathrm{ng} / \mathrm{ml}$ were added as an internal standard (resulting in a final concentration in the sample of $1 \mathrm{ng} / \mathrm{g}$ ).

The extract of each matrix was then passed through the IAC at a flow rate of $1 \mathrm{drop} / \mathrm{s}$. After a washing step with $20 \mathrm{ml}$ of PBS buffer solution, the column was dried for several seconds using draw vacuum. OTA was eluted in a glass tube with $1.5 \mathrm{ml}$ of methanol acified with acetic acid (98:2) and $1.5 \mathrm{ml}$ of deionised water. After vortexing, the eluate was transferred in a glass vial before LC-MS/MS analysis.

\section{Quantification}

For the quantification of OTA in salami, calibration curves were obtained using calibration solutions in solvent. The curves were generated from the peak area ratio between OTA and $\mathrm{U}-\left[{ }^{13} \mathrm{C}_{20}\right]$-OTA (IS). Eight calibration standards were prepared in the range of $0.01-10 \mathrm{ng} / \mathrm{ml}$, and a constant amount of internal standard (U- $\left[{ }^{13} \mathrm{C}_{20}\right]$-OTA) was added to all standards. The OTA contents of the samples were calculated by extrapolating the peak-area ratio to the calibration curve.

\section{Performance evaluation}

The performance of the method applied was assessed using standard OTA solutions in solvent, blanks and spiked samples. The evaluation of linearity was determined using OTA solutions at concentrations of $0.01,0.05,0.1,0.5,1,2$, 5 , and $10 \mu \mathrm{g} / \mathrm{kg}$, and it was checked using the coefficient

Table 1. Mass spectrometric parameters for the simultaneous determination of OTA and U- $\left[{ }^{13} \mathrm{C}_{20}\right]-$ OTA (IS) using an electrospray interface (ESI) in positive ionization mode.

\begin{tabular}{llllll} 
Analyte & MW $(\mathbf{g} / \mathrm{mol})$ & Retention time $(\mathrm{min})$ & Precursor ion $(\mathrm{m} / \mathbf{z})$ & Product ions $(\mathrm{m} / \mathbf{z})$ & Collision energy $(\mathrm{eV})$ \\
Ochratoxin A & 403.81 & 8.61 & 404.1 & 238.9 a & 22 \\
U-[ $\left.{ }^{13} \mathrm{C}_{20}\right]$-ochratoxin A & 423.67 & 8.61 & 424.0 & 358.1 & 13 \\
\hline${ }^{\text {a }}$ Quantification ion. & & & & 377.1 & 15 \\
\hline
\end{tabular}


of determination $\left(\mathrm{R}^{2}\right)$. Specificity and matrix effects were evaluated by analysis of blanks and spiked samples to verify the possible presence of interfering substances at the retention time of OTA. The recovery and repeatability experiments were carried out using samples spiked with OTA at levels of $0.5,1$, and $2 \mu \mathrm{g} / \mathrm{kg}$ by making 6 replicate measurements for a total of 18 determinations. The spiked samples were prepared and analysed by the same operators with the same instruments and on the same day. The recovery values were calculated by comparing the peak area ratio between OTA and $\mathrm{U}-\left[{ }^{13} \mathrm{C}_{20}\right]$-OTA in spiked samples and the peak area ratio between OTA and $\mathrm{U}-\left[{ }^{13} \mathrm{C}_{20}\right]$-OTA of pure standard solutions at the same concentration levels. The repeatability was expressed in terms of relative standard deviation (RSD \%) of the replicate measurements. The within-laboratory reproducibility was determined using samples spiked with OTA at levels of $0.5,1$, and $2 \mu \mathrm{g} / \mathrm{kg}$ by making 6 replicate measurements for each concentration on 3 different days (54 determinations in total), and RSD $\%$ of the replicate measurements was calculated. The limit of detection (LOD) and the limit of quantification (LOQ) were determined on the basis of a signal-to-noise ratio of 3:1 for the LOD and 10:1 for the LOQ.

\section{Results}

\section{Method validation}

Linearity was checked for all the calibration curves over the entire observed range $(0.01-10 \mu \mathrm{g} / \mathrm{kg})$, and the coefficient of determination $\left(R^{2}\right)$ was always $>0.99$. Under the analytical conditions described above, the specificity of the method was acceptable. Assay interference was investigated by injecting blank samples and spiked samples: no interfering peaks were observed around the retention time of OTA ( 8.5 $\mathrm{min})$. The run time was $11 \mathrm{~min}$. Supplementary Figure S1 shows a chromatogram obtained following the analysis of a naturally contaminated casing at $24 \mu \mathrm{g} / \mathrm{kg}$ level.

Recovery was checked at 3 spike levels, and the average recovery percentages ranged from 79.4 to $89.0 \%$, while the overall average recovery was $83.8 \%$. The data about the percent recoveries and the mean recoveries for each fortification level are shown in Table 2.

The repeatability was expressed as intra-day precision, and the RSDs of quantification results were in the range $8.1-15.8 \%$, while the within-laboratory reproducibility was expressed as inter-day precision, and the RSDs of quantification results ranged from 11.8 to $16.4 \%$ (Table 3).

These results comply with the performance criteria fixed by Regulation (EC) 401/2006 of the Commission of the European Communities (EC, 2006b). The LOQ and the LOD values obtained were 0.25 and $0.10 \mu \mathrm{g} / \mathrm{kg}$, respectively. These values underline the good level of sensitivity attained
Table 2. Recovery data of the method for analysis of ochratoxin A (OTA) in salami samples spiked at 3 concentration levels.

\begin{tabular}{|c|c|c|c|c|}
\hline & OTA spiking level ( $\mu \mathrm{g} / \mathrm{kg})$ & & & $M^{2}$ \\
\hline & 0.5 & 1 & 2 & \\
\hline Recovery $(\%)^{1}$ & 89.0 & 79.4 & 83.0 & 83.8 \\
\hline
\end{tabular}

Table 3. Results of repeatability and within-laboratory reproducibility tests (expressed as RSD\%) calculated for analysis of ochratoxin A (OTA) in salami samples. ${ }^{1}$

\begin{tabular}{|c|c|c|c|c|c|c|}
\hline \multirow[t]{2}{*}{$\begin{array}{l}\text { OTA spiking } \\
\text { level ( } \mu \mathrm{g} / \mathrm{kg})\end{array}$} & \multicolumn{3}{|c|}{ Repeatability } & \multicolumn{3}{|c|}{$\begin{array}{l}\text { Within-laboratory } \\
\text { reproducibility }\end{array}$} \\
\hline & $\begin{array}{l}\text { Mean } \\
(\mu \mathrm{g} / \mathrm{kg})\end{array}$ & $\begin{array}{l}\text { SD } \\
(\mu \mathrm{g} / \mathrm{kg})\end{array}$ & $\begin{array}{l}\text { RSD } \\
(\%)\end{array}$ & $\begin{array}{l}\text { Mean } \\
(\mu \mathrm{g} / \mathrm{kg})\end{array}$ & $\begin{array}{l}\text { SD } \\
(\mu \mathrm{g} / \mathrm{kg})\end{array}$ & $\begin{array}{l}\text { RSD } \\
(\%)\end{array}$ \\
\hline 0.5 & 0.46 & 0.07 & 15.8 & 0.45 & 0.07 & 16.4 \\
\hline 1 & 0.79 & 0.06 & 8.1 & 0.79 & 0.09 & 11.8 \\
\hline 2 & 1.60 & 0.24 & 14.7 & 1.66 & 0.26 & 15.6 \\
\hline
\end{tabular}

${ }^{1} \mathrm{SD}=$ standard deviation; RSD \% = relative standard deviation.

in the present work since they are 4 and 10 times lower than the Italian guideline value of $1 \mu \mathrm{g} / \mathrm{kg}$ established for OTA in pork meat and derived products. Taken together, these validation results show that the methodology applied in this study performed well in quantitating OTA in the products analysed.

\section{Occurrence of ochratoxin A in salami samples}

As reported above, in this study a total of 96 artisan salamis were analysed for the presence of OTA. Firstly, the casings of 83 salamis purchased at the start of the study ( 51 from Campania and 32 from Marche) were analysed, and 57 of them were negative, while 16 samples (11 from Campania and 5 from Marche) showed a concentration level of OTA ranging from the LOQ $(0.25 \mu \mathrm{g} / \mathrm{kg})$ to $23.8 \mu \mathrm{g} / \mathrm{kg}$. In particular, 5 out of these positives ( 2 from Campania and 3 from Marche) exceeded the guidance value of $1 \mu \mathrm{g} / \mathrm{kg}$ established for OTA by the Italian Ministry of Health, as shown in Table 4.

The edible part of these last 5 samples was then examined, and the outer portion and the core of each salami were analysed individually. OTA was detected in the outer edible part of 3 salamis, and in one of them also in the inner core. In two cases, the concentration found in the outer portion exceeded the guidance value of $1 \mu \mathrm{g} / \mathrm{kg}$ ( 3.9 and $5.7 \mu \mathrm{g} / \mathrm{kg}$, 
Table 4. Occurrence of ochratoxin A (OTA) on the casing of salami samples collected in the Campania and Marche regions at the first sampling.

$\begin{array}{lllll}\text { Region } & \begin{array}{l}\text { \# positives/ } \\ \text { \# total samples }\end{array} & \text { \% positives } & \begin{array}{l}\text { \# positives exceeding OTA guideline } \\ \text { value }(\mathbf{1} \boldsymbol{\mu g} / \mathrm{kg})\end{array} & \begin{array}{l}\% \text { positives exceeding OTA guideline } \\ \text { value }(\mathbf{1} \boldsymbol{\mu g} / \mathrm{kg})\end{array} \\ \text { Campania } & 11 / 51 & 21.6 & 2 & 3.9 \\ \text { Marche } & 5 / 32 & 15.6 & 3 & 9.4\end{array}$

respectively), while the OTA level detected in the inner part was $0.3 \mu \mathrm{g} / \mathrm{kg}$, that is slightly above LOQ (Table 5).

Since salami samples that showed the highest concentrations of OTA came from the same production plant located in the Marche region, an additional sampling was carried out in this site in order to assess the possible contamination of salamis of other types and from different batches. Thirteen further samples of sausage products were therefore collected, and analysis were carried out separately on the casing and on the outer and inner edible parts. OTA was found on the casing of 8 samples (equal to $61.5 \%$ of the products sampled), and 6 of them exceeded the Italian guidance value for OTA. The concentrations detected ranged from LOQ to $98.5 \mu \mathrm{g} / \mathrm{kg}$, while the mycotoxin was not found in the edible parts of any sample (Table 6).

Table 5. Concentration levels of ochratoxin A (OTA) in salamis whose casings exceeded the Italian guideline value for OTA (1 $\mu \mathrm{g} / \mathrm{kg}$ ).

\begin{tabular}{|c|c|c|c|c|c|}
\hline \multirow[t]{2}{*}{ Ref. } & \multirow[t]{2}{*}{ Region } & \multirow[t]{2}{*}{ Type of salami } & \multicolumn{3}{|c|}{ OTA levels ( $\mu \mathrm{g} / \mathrm{kg}$ ) } \\
\hline & & & Casing & Outer edible part & Inner edible part \\
\hline $\mathrm{C} / 7$ & Campania & Sopressata & 9.2 & 3.9 & 0.3 \\
\hline $\mathrm{C} / 50$ & Campania & Salame Corallina & 1.1 & $<\mathrm{LOQ}^{\mathrm{b}}$ & $<L O Q$ \\
\hline$M / 21^{a}$ & Marche & Salame Nostrano & 10.6 & $<L O Q$ & $<L O Q$ \\
\hline$M / 22^{a}$ & Marche & Salame Nostrano & 23.8 & 5.7 & $<L O Q$ \\
\hline$M / 30$ & Marche & Salame Suino & 4.1 & 0.3 & $<L O Q$ \\
\hline
\end{tabular}

a Samples from the same production plant.

${ }^{b} L O Q=$ limit of quantification.

Table 6. Ochratoxin A (OTA) levels in positive samples collected at the additional sampling carried out in the same production plant. ${ }^{1}$

\begin{tabular}{|c|c|c|c|c|c|}
\hline \multirow[t]{2}{*}{ Ref. } & \multirow[t]{2}{*}{ Region } & \multirow[t]{2}{*}{ Type of salami } & \multicolumn{3}{|c|}{ OTA levels $(\mu \mathrm{g} / \mathrm{kg})^{2}$} \\
\hline & & & Casing & Outer edible part & Inner edible part \\
\hline $\mathrm{M} I \mathrm{I} / 2 \mathrm{~A}$ & Marche & Ciauscolo & $24.3^{*}$ & $<L O Q$ & $<L O Q$ \\
\hline $\mathrm{M} \mathrm{II/2B}$ & Marche & Ciauscolo & $2.0^{*}$ & $<L O Q$ & $<L O Q$ \\
\hline $\mathrm{M} I I / 6 \mathrm{~A}$ & Marche & Salame Nostrano & $62.0^{*}$ & $<L O Q$ & $<L O Q$ \\
\hline M II/6B & Marche & Salame Nostrano & $98.5^{\star}$ & $<L O Q$ & $<L O Q$ \\
\hline M II/7A & Marche & Salame Nostrano & $7.7^{\star}$ & $<L O Q$ & $<L O Q$ \\
\hline M II/7B & Marche & Salame Nostrano & $4.2^{*}$ & $<L O Q$ & $<L O Q$ \\
\hline M II/8A & Marche & Salame al Cinghiale & 0.25 & $<L O Q$ & $<L O Q$ \\
\hline M II/8B & Marche & Salame al Cinghiale & 0.49 & $<L O Q$ & $<L O Q$ \\
\hline
\end{tabular}


Considering all the 96 sausage products examined, on the whole, OTA was detected on the casing of 24 samples, which account for a relatively high percentage $(25.0 \%$ of the total). However, the distribution of the concentration levels shows that more than $50 \%$ of the positive samples was in the concentration range $0.25-1 \mu \mathrm{g} / \mathrm{kg}$, and therefore did not exceed OTA guidance value (Figure 1).

\section{Discussion and conclusions}

The percentage of positive samples is slightly different in the two regions (21.6\% of samples from Campania, 15.6 or $28.9 \%$ of samples from Marche, depending on whether we consider only the data about the first sampling or even the additional sampling). However, there are no elements to say that these differences are related to the production area.

The two regions have quite different climates. The entire production process of sausages is significantly affected by the climatic conditions, and in particular the dryingmaturing process during which the growth of microflora characteristic of the geographical environment occurs. Moreover, other differences between the products from the two areas concern raw materials, ingredients and preparation methods. However, what all sausages examined have in common is that they were purchased from farms in which pigs were reared using traditional livestock-farming methods in a wild and semi wild state, using a diet based on wheat bran and household food scraps (such as potatoes, apples and tomato skins). The casings used in sausage production were mainly of natural origin and no mould

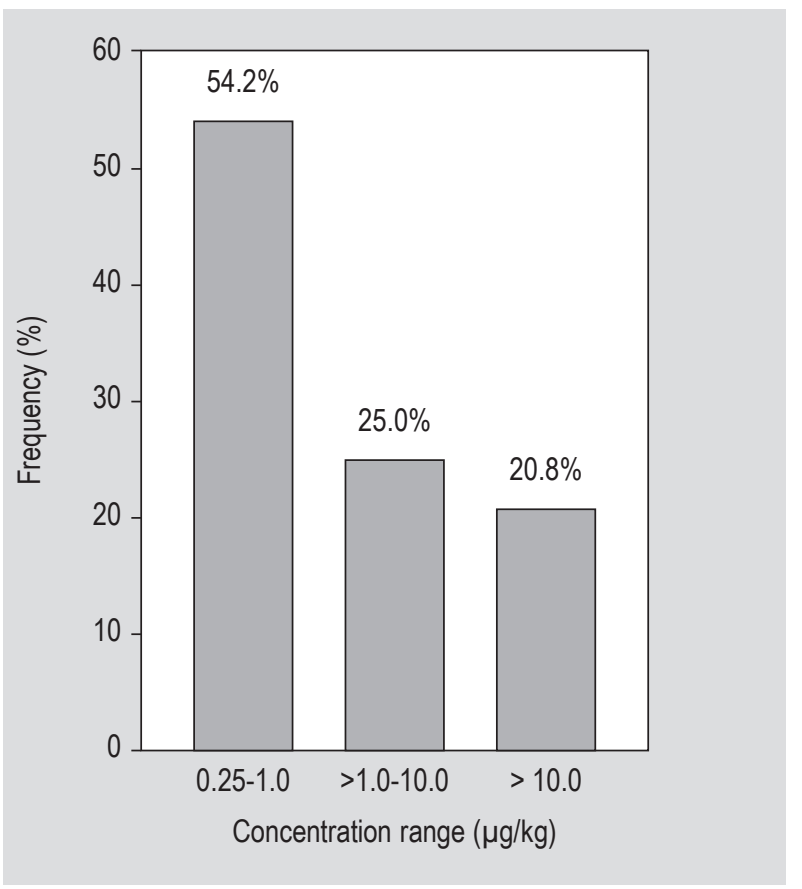

Figure 1. Distribution of ochratoxin A (OTA) levels detected on the casings of the positive samples. starters were added for the fermentation process and mould cover formation.

The edible parts of the salamis were mostly uncontaminated and this would mean that the diet administered to animals from which raw material for sausages production derive was safe, at least as regard OTA contamination, while the presence of the mycotoxin on the casings could be due to an environmental contamination. Thus, the high percentage of sausage products from the same farm in which OTA was detected on the casing is probably due to mycotoxigenic moulds originating from the indoor air of the dehydrating and ripening rooms. This is not a situation common to the sausage products from the Marche region, but it is a problem of contamination linked to a single production plant.

Several studies have been carried out to monitor the presence of OTA in pork meat-derived products. The main results reported by some authors are summarised in Table 7 .

Based on the present data and the results of previous studies, some further interesting consideration can be made in evaluation of OTA risk in cured meat products. Indirect contamination of pork products due to transmission of OTA from animals exposed to contaminated feed, although it has been largely demonstrated experimentally, occurs rarely (Iacumin et al., 2009, 2011; Pietri et al., 2006). Otherwise, direct contamination with toxigenic moulds of environmental origin is the most commonly reported cause for mycotoxin presence (Dall'Asta et al., 2010; Iacumin et al., 2009; Merla et al., 2018; Pietri et al., 2006; Pleadin et al., 2015; Rodríguez et al., 2012). However, the high contamination risk is greater in dry-cured ham than in sausage products either because of the long curing time or because of the fact that ham is not protected by the casing (Bertuzzi et al., 2013; Dall'Asta et al., 2010; Pleadin et al., 2015). It seems quite clear that the casing acts as a protective system against external contamination during ripening.

However, the results of several studies also indicate that OTA can cross the casing (Bertuzzi et al., 2013; Pietri et al., 2006; Spotti et al., 1999), but not always (Iacumin et al., 2009). Regarding this last question, the data of the present study show that in some cases, also in presence of very high levels of OTA on the casing, the mycotoxin was not detected in the edible parts (Table 6), while in others, the presence of OTA on the casing is associated to the detection of the mycotoxin in the sausage meat (Table 5). Furthermore, one of the positive samples (ref. C/7) was in artificial casing, showing that OTA was capable of diffusing also through this type of casing, according to Spotti et al. (1999). To prevent or limit this kind of contamination, the control of environmental parameters (physical and microbiological) is the most important measure that should be implemented (Comi et al., 2004). 
Table 7. Residual levels of ochratoxin A in in pork meat-derived products.

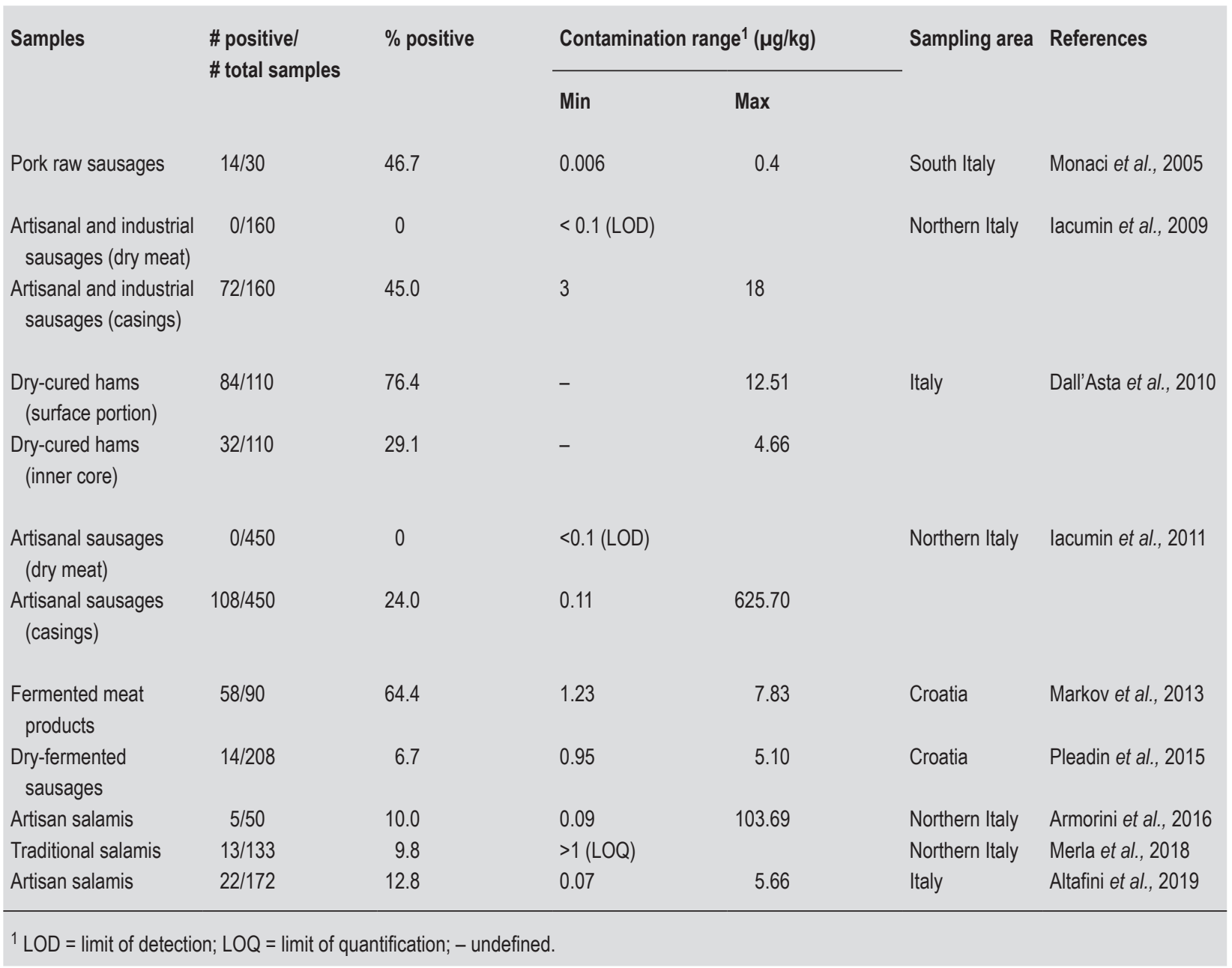

The production of OTA is in turn strain dependent and requires ad hoc conditions of temperature, humidity, water activity $\left(\mathrm{a}_{\mathrm{w}}\right)$, nutrients, and each fungal species has different optimal conditions for producing OTA (Merla et al., 2018). It has been demonstrated that uncontrolled and heterogeneous indigenous fungal population represents a serious risk of OTA accumulation in dry-cured meat products (Bernáldez et al., 2018). The most interesting methods developed to control OTA accumulation in these products are represented by bioprotective cultures of non-toxigenic moulds (Iacumin et al., 2017). Some other measures that can be taken to prevent or reduce OTA contamination are the removal of moulds from the product surfaces using various techniques (e.g. brushing, washing, or air pressure) and the spreading of rice flour on the casings (Iacumin et al., 2009; Pleadin et al., 2015). In addition to cleaning sausages physically, chemical antifungal agents, such as sodium benzoate, potassium sorbate, and methyl p-hydroxybenzoate can be used as superficial mould inhibitors (Martín-Sánchez et al., 2011; Matos et al., 2007).
However, in recent years the problem of possible health hazards linked to the use of chemical preservatives in foods has caused concern among consumers (Ingredients Insight, 2018). For this reason, the increasing trend is using natural preservatives (in the specific case, natural antifungals) instead of chemically synthetised compounds (Ribes et al., 2018). Among them, natamycin is a natural antifungal agent produced during the fermentation of the bacterium Streptomyces natalensis (Pipek et al., 2010). Some essential oils (EO) from plants such as oregano (Origanum vulgare) and basil (Ocimum basilicum L.) can be used as natural antifungals for the production of dry sausages without having detrimental effects on sensory properties (MartínSánchez et al., 2011; Saggiorato et al., 2012).

Also chitosan, a natural polycationic linear polysaccharide derived from chitin, was suggested as alternative natural antifungal agent. Chitosan solution $1 \%$, whether used singly or enriched with some EO (1\% thyme-EO or $1 \%$ rosemaryEO) has shown to be effective for the inhibition of surface mould growth without affecting the quality parameters of 
sausages (Arslan and Soyer, 2018; Soncu et al., 2018). Finally, another technique worth mentioning is treatment with ozonated air during drying and ripening. It was reported as an effective method to prevent potentially toxigenic mould contamination and growth (Comi et al., 2013; Iacumin et al., 2011, 2012). Furthermore, the use of ozone do not seem to influence the ripening, physico-chemical parameters, lipid oxidation or sensorial characteristics of the sausages (Iacumin et al., 2012).

However, these practices cannot always be implemented and in any case, care is needed in such approaches as they can cause the inhibition of growth of specific mould species or strains that play an important role, especially in the typical productions, for the development of characteristic flavours and aromas (Rodríguez et al., 2015).

In conclusion, the present study on the occurrence of OTA in artisan salamis showed that although also very high OTA levels were found on the surface of some products, only in two cases the concentration found in the edible portion exceeded the guidance value of $1 \mu \mathrm{g} / \mathrm{kg}$. On the whole, OTA was detected on the casing in $25.0 \%$ of the samples and even if this data is affected by the high number of positives samples found in one single farm, the percentage is nevertheless not negligible. The presence of OTA on the casing does not therefore seem to be cause for alarm about the safety of this type of product. However, it should be noted that sausages are sometimes sliced without removing the casing especially if it is very thin, also because on salamis labels the casing is often reported as edible. Moreover, even if it is removed from the slices before consumption, a contamination of the edible part from the outside via the knife blade might also be possible. Lastly, it is worth stressing the importance of monitoring the whole production chain of these food products in order to implement appropriate measures to prevent and minimise the health hazard due to this mycotoxin.

\section{Supplementary material}

Supplementary material can be found online at https://doi. org/10.3920/WMJ2020.2568.

Figure S1. Chromatogram obtained after LC-MS/MS analysis of a naturally contaminated casing at $24 \mu \mathrm{g} / \mathrm{kg}$ level representing the quantitation and confirmation MRM transitions.

\section{Conflict of interest}

The authors declare no conflict of interest.

\section{References}

Altafini, A., Armorini, S., Zaghini, A., Sardi, L. and Roncada, P., 2017. Tissue distribution of ochratoxin A in pigs after administration of two-levels contaminated diets. World Mycotoxin Journal 10: 263-272.

Altafini, A., Fedrizzi, G. and Roncada, P., 2019. Occurrence of ochratoxin A in typical salami produced in different regions of Italy. Mycotoxin Research 35: 141-148.

Armorini, S., Altafini, A., Zaghini, A. and Roncada, P., 2016. Ochratoxin A in artisan salami produced in Veneto (Italy). Food Additives and Contaminants Part B 9: 9-14.

Arslan, B. and Soyer, A., 2018. Effects of chitosan as a surface fungus inhibitor on microbiological, physicochemical, oxidative and sensory characteristics of dry fermented sausages. Meat Science 145: 107-113.

Associazione Industriali delle Carni e dei Salumi (ASSICA), 2018. Analisi del settore e dati economici 2017. L'Industria delle Carni e dei Salumi. ASSICA, Milan, Italy. Available at: https://tinyurl. com/y85nfat6

Battilani, P., Pietri, A., Giorni, P., Formenti, S., Bertuzzi, T., Toscani, T., Virgili, R. and Kozakiewicz, Z., 2007. Penicillium populations in dry-cured ham manufacturing plants. Journal of Food Protection 70: 975-980.

Bernáldez, V., Rodríguez, A., Delgado, J., Sánchez-Montero, L., Juan, J. and Córdoba, J.J., 2018. Gene expression analysis as a method to predict OTA accumulation in dry-cured meat products. Food Analytical Methods 11: 2463-2471.

Bertuzzi, T., Gualla, A., Morlacchini, M. and Pietri, A., 2013. Direct and indirect contamination with ochratoxin A of ripened pork products. Food Control 34: 79-83.

Castegnaro, M., Canadas, D., Vrabcheva, T., Petkova-Bocharova, T., Chernozemsky, I.N. and Pfohl-Leszkowicz, A., 2006. Balkan endemic nephropathy: role of ochratoxins A through biomarkers. Molecular Nutrition and Food Research 50: 519-529.

Comi, G., Chiesa, L., Panseri, S., Orlic, S. and Iacumin, L., 2013. Evaluation of different methods to prevent Penicillium nordicum growth on and ochratoxin A production in country-style sausages. World Mycotoxin Journal 6: 411-418.

Comi, G., Orlic, S., Redzepovic, S., Urso, R. and Iacumin, L., 2004. Moulds isolated from Istrian dried ham at the pre-ripening and ripening level. International Journal of Food Microbiology 96: 29-34.

Dall'Asta, C., Galaverna, G., Bertuzzi, T., Moseriti, A., Pietri, A., Dossena, A. and Marchelli, R., 2010. Occurrence of ochratoxin A in raw ham muscle, salami and dry-cured ham from pigs fed with contaminated diet. Food Chemistry 120: 978-983.

European Commission (EC), 2002. Assessment of dietary intake of ochratoxin A by the population of EU member states. Report of the Scientific Cooperation, Task 3.2.7. Directorate-General Health and Consumer Protection. EC, Brussels, Belgium. Available at: http:// tinyurl.com/mea7ar5

European Commission (EC), 2006a. Commission Recommendation of 17 August 2006 on the presence of deoxynivalenol, zearalenone, ochratoxin A, T-2 and HT-2 and fumonisins in products intended for animal feeding, 2006/576/EC. Official Journal of the European Union L 229: 7-9. 
European Commission (EC), 2006b. Commission Regulation EC No 401/2006 of 23 February 2006 laying down the methods of sampling and analysis for the official control of the levels of mycotoxins in foodstuffs. Official Journal of the European Union L 70: 12-34.

European Food Safety Authority (EFSA), 2006. Opinion of the Scientific Panel on Contaminants in the Food Chain on a request from the Commission related to ochratoxin A in food. EFSA Journal 365: 1-56.

Fongaro, L., Alamprese, C. and Casiraghi, E., 2015. Ripening of salami: assessment of colour and aspect evolution using image analysis and multivariate image analysis. Meat Science 101: 73-77.

Gil-Serna, J., Patiño, B., Cortes, L., Gonzalez-Jaen, M.T. and Vazquez, C., 2015. Aspergillus steynii and Aspergillus westerdijkiae as potential risk of OTA contamination in food products in warm climates. Food Microbiology 46: 168-175.

Hald, B., 1991. Porcine nephropathy in Europe. IARC Scientific Publications 115: 49-56.

Hassen, W., Abid, S., Achour, A., Creppy, E. and Bacha, H., 2004. Ochratoxin $A$ and $\beta_{2}$-microglobulinuria in healthy individuals and in chronic interstitial nephropathy patients in the Centre of Tunisia: a hot spot of ochratoxin A exposure. Toxicology 199: 185-193.

Iacumin, L., Chiesa, L., Boscolo, D., Manzano, M., Cantoni, C., Orlic, S. and Comi, G., 2009. Moulds and ochratoxin A on surfaces of artisanal and industrial dry sausages. Food Microbiology 26: 65-70.

Iacumin, L., Manzano, M. and Comi, G., 2012. Prevention of Aspergillus ochraceus growth on and ochratoxin A contamination of sausages using ozonated air. Food Microbiology 29: 229-232.

Iacumin, L., Manzano, M., Andyanto, D. and Comi, G., 2017. Biocontrol of ochratoxigenic moulds Aspergillus ochraceus and Penicillium nordicum by Debaryomyces hansenii and Saccharomycopsis fibuligera during speck production. Food Microbiology 62: 188-195. Iacumin, L., Milesi, S., Pirani, S., Comi, G. and Chiesa, L.M., 2011. Ochratoxigenic mold and ochratoxin A in fermented sausages from different areas in Northern Italy: occurrence, reduction or prevention with ozonated air. Journal of Food Safety 31: 538-545.

Ingredients Insight, 2018. Growing concern over additives in food. Ingredients Insight, Nottingham, UK Available at: https://tinyurl. com/y8a5dcfy

International Agency for Research on Cancer (IARC), 1993. Some naturally occurring substances: food items and constituents, heterocyclic aromatic amines and mycotoxins. IARC Monographs on the evaluation of carcinogenic risks to humans. Vol. 56. IARC, Lyon, France.

Joint FAO/WHO Expert Committee on Food Additives (JECFA), 1996.

Ochratoxin A. Toxicological evaluation of certain food additives and contaminants. Forty-four meeting of the Joint FAO/WHO Expert Committee on Food Additives. WHO Food Additives Series 35, World Health Organization, Geneva, Switzerland.

Jørgensen, K., 2005. Occurrence of ochratoxin A in commodities and processed food - a review of EU occurrence data. Food Additives and Contaminants, Suppl. 1: 26-30.

Markov, K., Pleadin, J., Bevardi, M., Vahčić, N., Sokolić-Mihalak, D. and Frece, J., 2013. Natural occurrence of aflatoxin $\mathrm{B}_{1}$, ochratoxin A and citrinin in Croatian fermented meat products. Food Control 34: 312-317.
Martín-Sánchez, A.M., Chaves-López, C., Sendra, E., Sayas, E., Fenández-López, J. and Pérez-Âlvarez, J.Á., 2011. Lipolysis, proteolysis and sensory characteristics of a Spanish fermented dry-cured meat product salchichón with oregano essential oil used as surface mold inhibitor. Meat Science 89: 35-44.

Matos, T.J.S., Jensen, B.B., Bernardo, F.M.A., Barreto, A.H.S. and Hojberg, Ø., 2007. Mycoflora of two types of Portuguese dry-smoked sausages and inhibitory effect of sodium benzoate, potassium sorbate, and methyl p-hydroxybenzoate on mold growth rate. Journal of Food Protection 70: 1468-1474.

Meftah, S., Abid, S., Dias, T. and Rodrigues, P., 2018. Effect of drysausage starter culture and endogenous yeasts on Aspergillus westerdijkiae and Penicillium nordicum growth and OTA production. LWT - Food Science and Technology 87: 250-258.

Merla, C., Andreoli, G., Garino, C., Vicari, N., Tosi, G., Guglielminetti, M.L., Moretti, A., Biancardi, A., Arlorio, M. and Fabbi, M., 2018. Monitoring of ochratoxin A and ochratoxin-producing fungi in traditional salami manufactured in Northern Italy. Mycotoxin Research 34: 107-116.

Ministero della Sanità, 1999. CIRCOLARE 9 giugno 1999, n.10. Direttive in materia di controllo ufficiale sui prodotti alimentari: valori massimi ammissibili di micotossine nelle derrate alimentari di origine nazionale, comunitaria e Paesi terzi. Gazzetta Ufficiale 135. Available at: https://tinyurl.com/y8q4uqzg (in Italian)

Mitchell, N.J., Chen, C., Palumbo, J.D., Bianchini, A., Cappozzo, J., Stratton, J., Ryu, D. and Wu, F., 2017. A risk assessment of dietary ochratoxin A in the United States. Food and Chemical Toxicology 100: 265-273.

Monaci, L., Palmisano, F., Matrella, R. and Tantillo, G., 2005. Determination of ochratoxin A at part-per-trillion level in Italian salami by immunoaffinity clean-up and high-performance liquid chromatography with fluorescence detection. Journal of Chromatography A 1090: 184-187.

Pavlović, N.M., 2013. Balkan endemic nephropathy - current status and future perspectives. Clinical Kidney Journal 6: 257-265.

Perši, N., Pleadin, J., Kovačević, D., Scortichini, G. and Milone, S., 2014. Ochratoxin A in raw materials and cooked meat products made from OTA-treated pigs. Meat Science 96: 203-210.

Pfohl-Leszkowicz, A., Tozlovanu, M., Manderville, R., Peraica, M., Castegnaro, M. and Stefanovic, V., 2007. New molecular and field evidences for the implication of mycotoxins but not aristolochic acid in human nephropathy and urinary tract tumor. Molecular Nutrition and Food Research 51: 1131-1146.

Pietri, A., Bertuzzi, T., Gualla, A. and Piva, G., 2006. Occurrence of ochratoxin A in raw ham muscles and in pork products from northern Italy. Italian Journal of Food Science 1: 1-8.

Pipek, P., Rohlík, B.A., Lojková, A. and Staruch, L., 2010. Suppression of mould growth on dry sausages. Czech Journal of Food Sciences 28: 258-263.

Pleadin, J., Kudumija, N., Kovačević, D., Scortichini, G., Milone, S. and Kmetič, I., 2016. Comparison of ochratoxin A levels in edible pig tissues and in biological fluids after exposure to a contaminated diet. Mycotoxin Research 32: 145-151. 
Pleadin, J., Staver, M.M., Vahčić, N., Kovačević, D., Milone, S., Saftić, L. and Scortichini, G., 2015. Survey of aflatoxin B1 and ochratoxin A occurrence in traditional meat products coming from Croatian households and markets. Food Control 52: 71-77.

Ribes, S., Fuentes, A., Talens, P. and Barat, J.M., 2018. Prevention of fungal spoilage in food products using natural compounds: a review. Critical Reviews in Food Science and Nutrition 58: 2002-2016.

Rizzo, A., Eskola, M. and Atroshi, F., 2002. Ochratoxin A in cereals, foodstuffs and human plasma. European Journal of Plant Pathology 108: 631-637.

Rodríguez, A., Capela, D., Medina, Á., Córdoba, J.J. and Magana, N., 2015. Relationship between ecophysiological factors, growth and ochratoxin A contamination of dry-cured sausage based matrices. International Journal of Food Microbiology 194: 71-77.

Rodríguez, A., Rodríguez, M., Martín, A., Delgado, J. and Córdoba, J.J., 2012. Presence of ochratoxin A on the surface of dry-cured Iberian ham after initial fungal growth in the drying stage. Meat Science 90: 728-734.

Saggiorato, A.G., Gaio, I., Treichel, H., De Oliveira, D., Cichoski, A.J. and Cansian, R.L., 2012. Antifungal activity of basil essential oil (Ocimum basilicum L.): evaluation in vitro and on an Italian-type sausage surface. Food Bioprocess Technology 5: 378-384.
Schiavone, A., Cavallero, C., Girotto, L., Pozzo, L., Antoniazzi, S. and Cavallarin, L., 2008. A survey on the occurrence of ochratoxin A in feeds and sera collected in conventional and organic poultry farms in Northern Italy. Italian Journal of Animal Science 7: 495-503.

Soncu, E.D., Arslan, B., Ertürk, D., Küçükkaya, S., Özdemir, N. and Soyer, A., 2018. Microbiological, physicochemical and sensory characteristics of Turkish fermented sausages sucuk coated with chitosan-essential oils. LWT - Food Science and Technology 97: 198-204.

Sonjak, S., Ličen, M., Frisvad, J.C. and Gunde-Cimerman, N., 2011. Salting of dry-cured meat - a potential cause of contamination with the ochratoxin A-producing species Penicillium nordicum. Food Microbiology 28: 1111-1116.

Spotti, E., Cacchioli, C., Colla, F., Beatrisotti, M. and Zanardi, S., 1999. Growth of Penicillium verrucosum in model systems based on raw ripened meat products. Ochratoxin A determination and control. Industrie Conserve 74: 113-123.

Stiborová, M., Arlt, V.M. and Schmeiser, H.H., 2016. Balkan endemic nephropathy: an update on its aetiology. Archives of Toxicology 90: 2595-2615. 